\title{
COCKPITS TO CLASSROOMS - THE UNIQUE CHALLENGES FACED BY POSTGRADUATE STUDENTS SERVING IN THE MILITARY
}

\author{
B. Hargrave, K. Jacques, D. Cobham \\ University of Lincoln (UNITED KINGDOM)
}

\begin{abstract}
The University of Lincoln in the UK lies in close proximity to several military airbases. The School of Computer Science at the University of Lincoln offers taught postgraduate programmes designed for serving military personnel, delivered in partnership with the education department at one of those airbases. Almost without exception, our military students require interruptions and/or extensions to their studies before they are able to complete their programme. Some students have been 'on our books' for a number of years and it is possible that some of them may never complete their studies.
\end{abstract}

This paper examines some of the reasons why military students find it so difficult to complete their studies and how Higher Education Institutions (HEls) might improve the ways in which they support military students. The theoretical underpinning of the paper draws on several theories of motivation and also uses Schlossberg's, [1], (2005) ideas of adult transitions and support to analyse the unique challenges faced by students in the military.

This work is informed by the results of a survey of military students; questions in the survey were designed based on the Schlossberg $4 S$ transition model. This survey was followed up with a number of semi-structured interviews conducted with selected respondents.

The initial results of this research appear quite revealing. For example, military students are used to living and working in extremely disciplined environments where high standards and strict timescales must be strictly adhered to. Not doing so can, in many cases, risk life and limb. When presented with the more open environments that self-directed study in a HEl offer, these same students suffer a lack of focus and direction which has a detrimental impact on their engagement.

By promoting independent learning and directing ownership of the process of study to the student, it may be that we inadvertently hinder them in their pursuit of higher qualifications. Respondents report that some semblance of 'military discipline' is preferred when it comes to things like hand-in dates and the maximum time allowed to complete the programme.

Military students are justifiably proud of all that they have achieved in their military service. In some cases, however, this may lead them to the unrealistic belief that a Master's degree will naturally follow or automatically become theirs by right. Some military students may not readily accept the discovery, early on in the programme, that working at Master's level requires new and different skills. One challenge for programme providers, therefore, is to find ways to demonstrate the benefits that come from modifying ingrained ways of thinking. One way of doing this is by helping military students to develop and apply these new skills in the analysis of the real problems that they encounter in their military life.

Keywords: Schlossberg, transition, military, postgraduate, United Kingdom.

\section{INTRODUCTION}

The University of Lincoln in the UK lies in close proximity to several military airbases. The School of Computer Science at the university offers several MSc programmes for serving military personnel. One of these programmes is the MSc in Intelligence, Surveillance and Reconnaissance Management (ISRM). This programme is only open to military students as they undertake a seven month course delivered at RAF Waddington - a Royal Air Force base about five miles from the University of Lincoln.

Whilst our military students are on their course at RAF Waddington, they attend four day schools with us at the university. Once their military course is complete, they remain as part time MSc students of the university and have a further eighteen months to complete their award. To date, there have been 
twenty nine students enrolled on this MSc programme, none of whom have completed the award inside the time allowed. However, only one student has failed the programme and this failure was due to the student not meeting pass criteria in the exams that form part of the seven month military course. From the remaining cohort of twenty eight students who have enrolled on the MSc programme, four have graduated, two have withdrawn and seven are currently interrupted due to personal or military duty reasons

\section{MILITARY EDUCATION}

The men and women serving in the UK military represent a subset of the UK population and are drawn from all the strata that make up that population. It has been suggested, for example by De Czege [2], (1997), that the behaviour of the military, particularly in regard to education and the generation of knowledge, can be characterised as something deeply engrained in military culture.

Research about the transitions that military personnel undergo tends to concentrate on those transitions that occur when they leave the military. A large body of this research, for example Ashcroft, [3], (2014), concentrates on the failure of some UK ex-military personnel to make this transition a 'success' and points to the number of ex-military personnel who end up homeless and living rough on the streets. Much of the research that does exist in this area examines the particular case of the US military (for example, Diramio, et al, [4], (2008)) and it may be that findings from US military personnel are not necessarily applicable to military personnel in the UK.

By comparison with what might be termed the 'bad news', little research exists at the 'good news' end of the scale looking, in this instance, at the transition experience of serving UK personnel when they set out to gain postgraduate qualifications. It may be postulated that military personnel, as they approach the end of their time in the military, see gaining a postgraduate qualification as a way to ease their pathway to well-paid employment in civilian life. However, there may be many other motivations - some subtle and others not so subtle - that lead them to set out on this course. Motivations, however, may only be part of the story. The theoretical underpinning of this short paper will draw on theories of motivation, but also use the ideas of Schlossberg, (1981 [5] and 2005 [1]) regarding adult transitions and support to analyse the unique challenges faced by students in the military.

Military personnel are - probably with considerable justification - proud of what they have learned and achieved during their military service and may be surprised to discover that Higher Educational Institutions (HEls) in the UK are not queuing up to offer them impressive sounding qualifications based on their prior learning. They may also discover that many UK HEls have very little idea of what that learning may amount to or the value it may have in gaining credit towards a university degree. The same ex-military personnel, in possession of several Enhanced Learning Credits (ELCs) worth up to a total of $£ 6,000$, may also be surprised to learn that this may be an insufficient amount to cover the fees for a degree programme. At the time of writing, fees for a full-time undergraduate student starting at a UK university are $£ 9,000$ per year for what is, typically, a three year programme.

In comparison with the 'GI Bill' funding available to many ex-military personnel in the USA, the ELC funding available to even the most senior (in terms of time served) UK service leaver seems paltry. For example, under the rules of the post 9/11 GI Bill (Ch 33), US service personnel after 3 years' service become eligible for funding that will cover their full time fees/tuition at many colleges, pay them a housing benefit of $\$ 1,488$ per month and give them a book stipend of $\$ 1,000$ per year.

Under current rules, UK service personnel require a minimum of eight years' service to gain access to three ELCs, each worth £2000. A lower level of ELC - £1,000 - is available to those who have a minimum of four years' service. Only one of these three ELCs can be used in each year and ELCs cannot be used to cover the full cost of the fees. The service man or woman must make a 'personal contribution' amounting to $20 \%$ of the annual fees, with the ELC covering the remaining $80 \%$. From this it can be seen that, in order to access the full £2000 per year, fees must be a minimum of $£ 2,500$ p.a. $(80 \%$ of $£ 2,500$ is $£ 2,000)$. If the fees are exactly $£ 2,500$ p.a., then the UK service leaver must make a personal contribution of $£ 500$ each year.

Additionally, "the ELC element includes VAT but excludes travel, accommodation, food, books and materials. There is no entitlement to travel at public expense for ELC training activity, unless the ELC is drawn for resettlement purposes". An additional constraint, for those who wish to access their ELC entitlement whilst still serving, is that "The learning purpose must benefit the Service and advance the individual's development plans". 
When the level of ELC funding was first set in April 2000, £2,000 p.a. may (perhaps to some) have seemed a generous level of funding. However, in the intervening years, this funding has remained static and does not match either the $£ 9,000$ p.a. fees for a three year full-time Bachelor's degree or the (roughly) £9,000 p.a. fee for a typical one year full-time Master's degree.

The foregoing is not intended to suggest that "it's all about money". It is likely that "money" (in the context of course fees and the funds available to meet them) may be one factor. However, research should examine how much of a factor it is and, just as importantly, what other factors may be significant.

\section{THE MILITARY AS A UNIQUE CASE}

Vitas, [6], (1999) discusses civilian graduate education (education at civilian Higher Education Institutions or HEls) and draws a distinction between this and Professional Military Education (PME), the term which he and many others (the UK military included) use to refer to education carried out within the military - for instance at military academies (e.g. West Point in the US) and at what the US military refer to as 'war colleges' (the UK military uses the term 'staff colleges' to describe what are roughly the same type of establishment).

Much of the academic literature on the subject of PME and (or, sometimes, versus) civilian military education does appear to come from sources in the US. For instance, Davis, [7], (1989) in his article on 'The Case for Officer Professional Military Education', asks 'What do we think the purpose of PME is for any officer?" and "What should PME teach us?". Again, Davis's article is written from his point of view as a Lieutenant Colonel in the United States Air Force (USAF).

Davis is writing in 1989 (towards the end of the Cold War) and provides an interesting comparison with the way in which he believes PME was viewed by the USAF at the time, "... we can perhaps conclude that Air Force officers view PME only as a step towards promotion. Rarely do they acknowledge its intended functions - a means of enhancing professional competence." He contrasts this with the way in which PME worked then, in the Soviet Union:

"The faculty of Soviet PME schools, unlike that in our [the United States'] system, is directly involved in the development of military doctrine and strategic planning. Soviet officers, including flag ranks, must pass a competitive entrance examination to qualify for selection and, depending on the school, attend for two to five years - much longer than our usual 10 months. In order to graduate, they must defend a thesis on a military subject."

De Czege, [2], (1997) characterises the behaviour of the military, particularly in regard to education and the generation of knowledge, as something deeply engrained in military culture: "We are a pragmatic Army. We pride ourselves in our ability to solve problems, to improvise solutions and to devise new methods based on a process of rational examination of the readily apparent elements of the problem." However, he goes on to point out a deep flaw in this military approach when he says that "We discount the role of theory in our business because, as action-oriented individuals, we have little time for it. We tinker our way into new methods, new procedures, new force structures and new weapons. We simply discard and forget the old." Part of the solution proposed to the problem that De Czege identifies may lie within a robust education system.

The idea of a culture that is specific, or even unique, to the military may be an important one in any attempt to make university programmes more accessible to military students. Bower's, [8], (1996) definition of an organisational culture as 'the way we do things round here' is a useful shorthand for what Handy, [9] (1985) has described as the 'deep-set beliefs about the way work should be organised, the way authority should be exercised....'. Handy also asks 'do work hours matter, or dress, or personal eccentricities?'. In doing so, he inadvertently identifies three of the more obvious differences between the military environment and that of a UK university. These (seemingly unimportant) differences are commented on by all of the respondents to our survey. They may become more important when they form part of the 'mixed messages' that military students get from the university.

A key example of this would be the enduring problem that our administrative mechanisms have in recognising military postgraduate programmes as something different from the vast bulk of other programmes offered by the university. The military may not immediately recognise this, but university administrators derive great comfort from the ordered way in which the majority of students (both undergraduate and postgraduate) enrol on programmes in the autumn and then follow the ebb and flow of the standard academic year. In contrast, military students join our programme at any number of 
various points throughout the academic year and then blatantly fail to recognise the summer as a time when nothing very much happens. This only becomes a problem when, sometimes just a few weeks after they have first enrolled and paid their fees, they start to be bombarded with automatically generated demands from Student Services that they enrol and pay their fees again. The standard answer of 'just ignore anything our administrators send you and forward it to us' does not always send the most professional message.

Earlier mention of the Cold War raises an important point. Before the fall of the Berlin Wall and the subsequent apparent rapid collapse of the Soviet Union, many (if not most) in the UK and US military had no direct experience of combat. However, in the last twenty or more years, the picture has changed completely - most of those who have served in this period in the US and UK military will now have either experienced combat at first hand or, at least deployed to operational theatres in support of combat operations. Di Ramio et. al. [10], (2008) acknowledge this point when they ask "what needs do veterans bring to the campus?" and use Schlossberg's, [5], (1981) model of adult transition in an attempt to better understand the needs of students making the transition from wartime service to college. Whilst the study conducted by Di Ramio et. al. [10], concentrated exclusively on students who had left military service in the US Armed Forces, their work may also have relevance to the experiences of military and recently retired military studying part-time postgraduate courses at a UK university. Di Ramio et. al. believe that the results of their work "will help institutions organize a holistic approach for assisting veterans and improving their chances for success."

The brief review thus far suggests a number of points:

- That a distinction should be drawn between professional military education (PME) that happens within the military and civilian graduate education (CGE) that happens in universities and colleges.

- That CGE may help to address some of the perceived shortcomings of PME, or may, perhaps, be used to complement it.

- And that, perhaps most importantly, the needs of the military/ex-military student may be different to those of students from non-military backgrounds and one (of many?) reasons for this may be the likelihood of the military student's previous exposure to combat.

The other important conclusion that may, perhaps, be drawn is that the 'military education experience' varies by country (a comparison was made earlier between PME in the USA and PME in the old Soviet Union). This may also highlight a weakness in looking almost exclusively at literature on this subject from one nation (the USA) and using it to form hypotheses for military students at a university in a different nation (in this case, the UK). Many differences, not least cultural and institutional differences, may exist.

\section{MOTIVATION}

Pritchard and Ashwood, [11], (2008) define motivation as the process used to allocate energy to maximise the satisfaction of needs. Theories of human motivation fall, broadly, into two types: intrinsic and extrinsic. Intrinsic motivation is driven by interest or enjoyment in a task or activity that is being undertaken itself. It does not depend, they suggest, on the desire for reward. Extrinsic motivation entails undertaking a task or activity because of the desire to attain an outcome or reward.

Maslow, [12], (1943) proposed one of the best known theories of motivation, commonly known as the 'hierarchy of needs' and represented in fig 1 below. Maslow postulated that each of the needs in the lower levels of his hierarchy must be satisfied and only then are human beings motivated to move to the level above, and to start to satisfy those needs. Military MSc students at the university have reported that one of their reasons for embarking on the programme is to gain recognition for skills and competences that they already have and, also, to prove to those who do not know them by reputation that they do, actually, possess those skills and competences. 


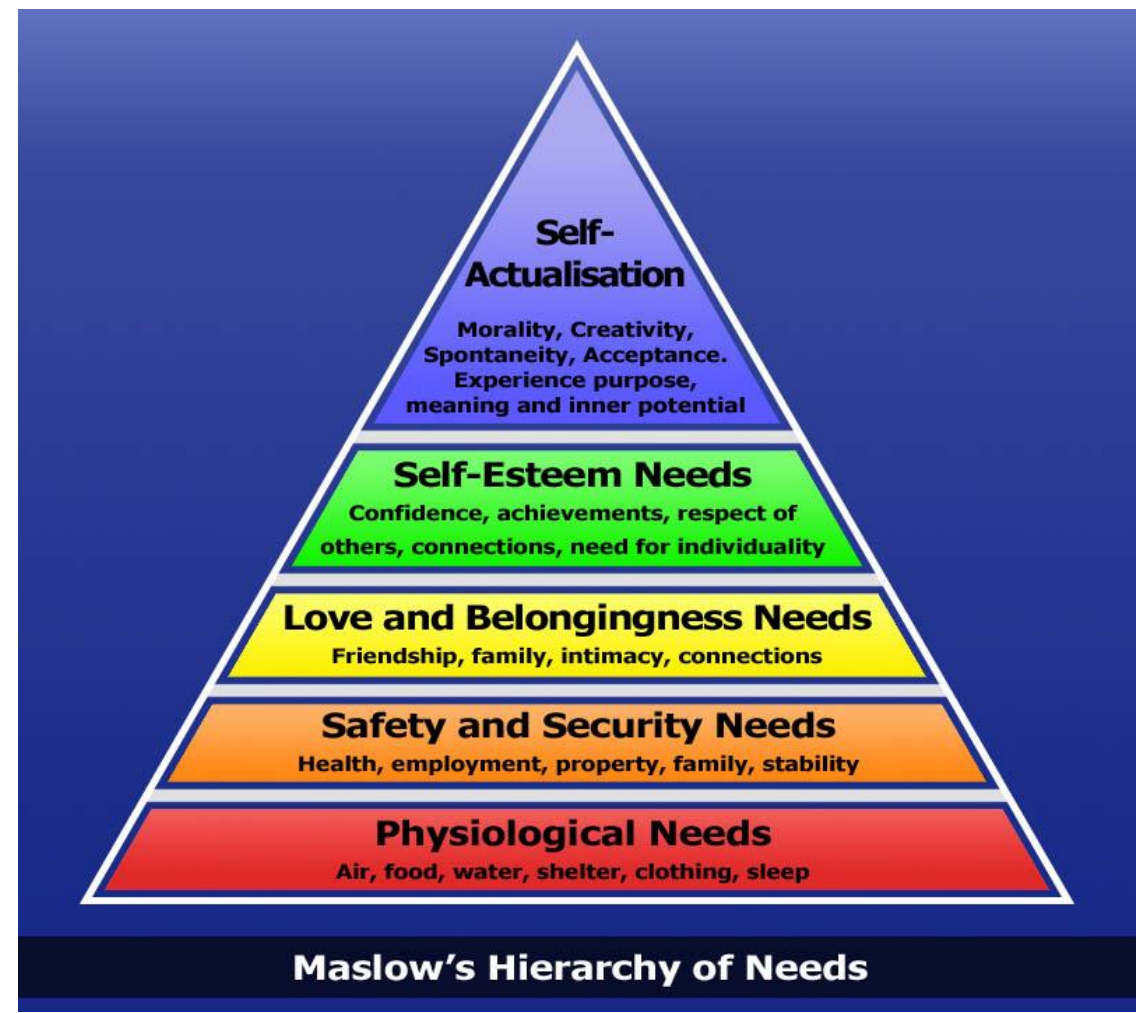

Fig. 1. Maslow's [12] Hierarchy of Needs

This reason (or related reasons) seems to be based in the 'self-esteem' needs of fig 1.

Herzberg's, [13], (1966) two-factor theory of motivation proposed two types of factors that contribute to job-satisfaction. The two types of factors introduced by this theory are motivator factors (e.g. challenging work, recognition and responsibility) and hygiene factors (e.g. good salary, comfortable working environment and other benefits). However, the absence of some factors does not result in dissatisfaction, but instead in a state of no satisfaction. Hygiene factors were so-called because the existence of hygiene does not directly improve health and well-being, but the absence of hygiene may result in ill-health. By this analogy, the lack of a good salary, comfortable working environment etc. will result in demotivation. Herzberg also identifies one factor that remains constant - the reported need of "respect for me as a person". Rosenberg and McCullough, [14], (1981) coined the term 'mattering' to describe something similar - the need to feel that others appreciate and value what you do.

Alderfer, [15], (1969) proposed an alternative to Maslow's [12] hierarchy of needs in his Existence, Relatedness and Growth (ERG) theory of motivation. He suggested that Existence, Relatedness and Growth encapsulated the needs of human beings, but also disputed Maslow's assumption that the satisfaction of lower-level needs was required before the higher-order needs emerged. Importantly, in the context of the aims of this paper, Alderfer [15] suggests that growth needs are part of an intrinsic desire for personal development which incorporates aspects of Maslow's self-esteem needs and combines them with aspects of Maslow's self-actualisation needs.

Achievement motivation has been studied extensively by McClelland, [16], (1987) who suggests that the motivation to achieve something is due to the way in which components of a human being's personality are directed towards performance. McClelland suggested that all humans had three motivators or needs - a need for achievement, a need for affiliation and a need for power.

Schuler et. al. [17] (2004) applied McClelland's work to devise the Achievement Motivation Inventory (AMI) which measures seventeen dimensions of work related achievement motivation. At least three of these seventeen dimensions appear to be directly related to motivation to pursue postgraduate study and these are: Eagerness to learn, Preference for difficult tasks and Status orientation. The findings of this initial research appear to bear this out. 


\section{ADULT TRANSITIONS}

Schlossberg, [5], (1981), defines a transition as something that can be said to occur "...if an event or non-event results in a change in assumptions about oneself and the world and thus requires a corresponding change in one's behaviour and relationships." She proposes a model for analysing human adaptation to transition and goes on to explain that "...the term transition as used in this model is defined broadly to mean not only obvious life changes such as high school graduation, job entry, marriage, birth of the first child, and bereavement, but also such subtle changes as the loss of one's career aspirations and the non-occurrence of anticipated events...".

Schlossberg's so-called $4 S$ model suggests that successful adaptation to transition depends on a person's Situation, the resources they bring to that situation - their Self, the amount and nature of the

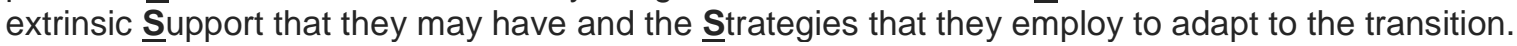
The model is grounded in a counselling approach that may be well suited to the close working relationship between a postgraduate student and his or her academic supervisor.

Schlossberg's model has been widely applied, for instance by Swain, [18], (1991) who applied it to withdrawal from sport, Beausoleil-Holt, [19], (2008) who applied it in facilitating the success of soldiers in degree programmes and Ryan, [20], (2010) who applied it to the transition of US military veterans to Higher Education . The model would therefore seem to be applicable to military personnel embarking on a postgraduate programme at a $\mathrm{HEl}$.

\section{EMERGING HYPOTHESES AND RESEARCH QUESTIONS}

The brief review of the literature conducted so far raises a number of interesting areas for primary research. These include:

- Why do military students choose to pursue CGE? Might there be a difference between their stated reasons and their actual reasons?

- What do students deem to be their measures of success as a result of CGE?

- To what extent does the UK military establishment value and reward those who have undertaken CGE?

- What advantages does (or might) CGE offer to the UK Armed Forces?

- In what way do the needs of military (or recent ex-military) CGE students differ from those of non-military CGE students?

The hypotheses that are proposed from these research questions, in the light of the literature reviewed thus far are:

H1: $\quad$ Military and ex-military students predominantly choose CGE in order to gain recognition for their existing skills, knowledge and competences. This may then prove problematic when students discover that they must learn new skills, knowledge and competences. In effect, this is an 'adult transition' and may be analysed via Schlossberg's model of human adaptation to transition.

H2: $\quad$ Students measure their CGE success in terms of effect: e.g. career progression, promotion or getting a better job, not in terms of the degree they are awarded.

H3: $\quad$ A UK military culture exists which is sufficiently distinct from UK culture. Understanding this military culture will enable universities to better meet the needs of military students. 


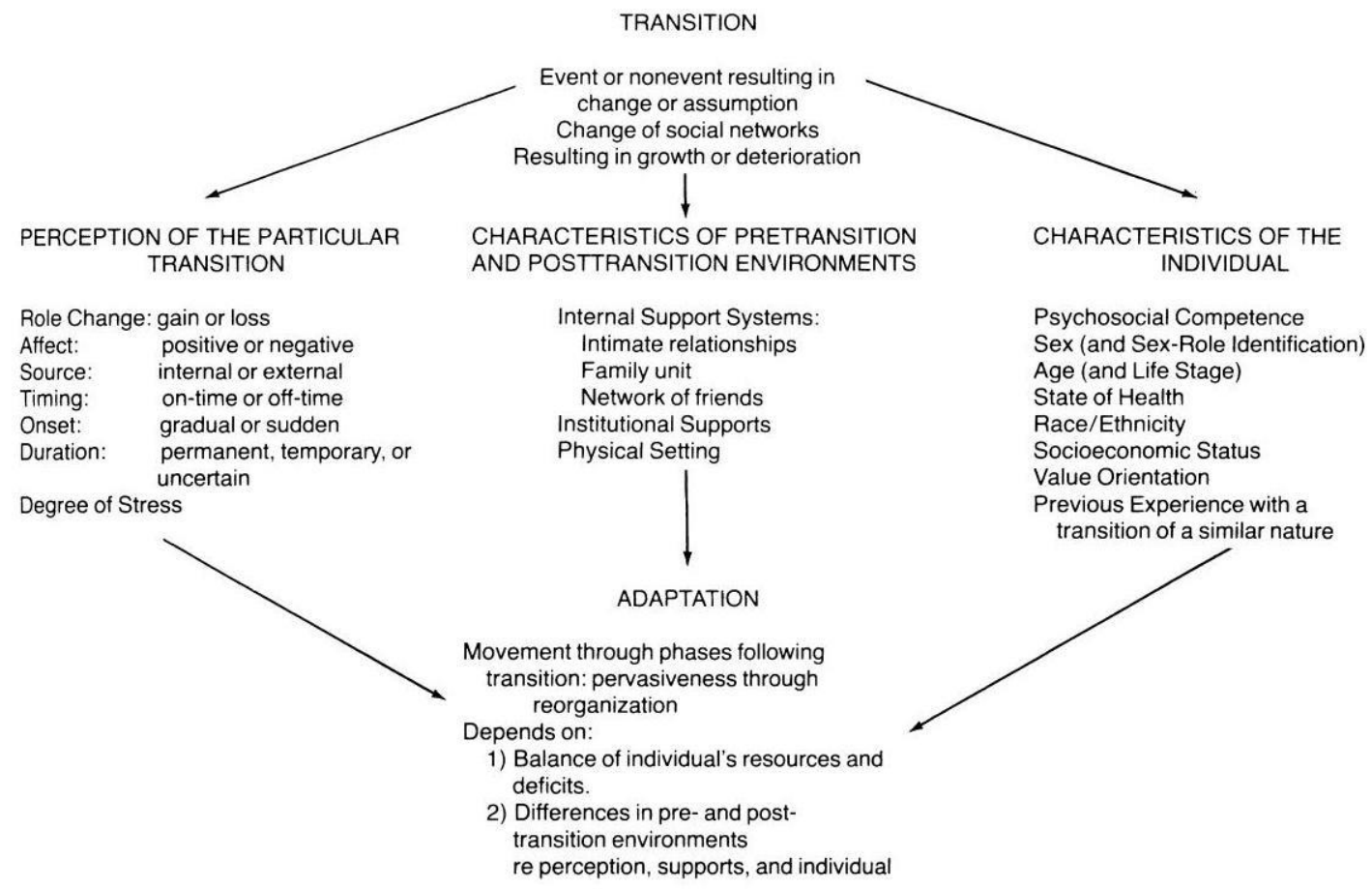

Figure 2. Schlossberg's [1] model for analysing human adaptation to transition

\section{METHODOLOGY}

The research has taken a classical mixed methods approach to gathering data from a small population of military postgraduate students at the University of Lincoln in the UK. In doing so, the research drew on the 4S model of adult transitions postulated by Schlossberg, [1]. This model is used in counselling practice (particularly in the US where, strangely, they spell counselling with only one ' $L$ ') to assist those adjusting to transitions. The model identifies four factors which determine an individual's capacity to make a successful transition:

$\begin{array}{ll}\text { - } & \text { Situation } \\ \text { - } & \text { Self } \\ \text { - } & \text { Support } \\ & \text { Strategies. }\end{array}$

The researchers have been in email contact with Goodman, [20], (2011). Goodman is one of the coauthors, (with Schlossberg and Anderson), of practical applications of the 4S model. As a result of this, work has been done to design a set of questions which 'operationalise' each of the four factors in the model (listed above) in the context of military postgraduate study. This set of questions was piloted with four military postgraduate students at this university and amendments made to the questionnaire in the light of respondent feedback.

\section{FINDINGS AND CONCLUSIONS}

Of the nineteen students surveyed, seven had replied by the time of writing. Motivations to study, at least in terms of answers to the survey, were varied, but a majority were based around getting a good job once they leave the military (six out of seven respondents agreed with this statement) and five out of seven also wanted a Master's degree as concrete recognition of the skills and experience they had gained in the military. Four out of the seven respondents felt that having the qualification would enhance their promotion prospects within the military. Respondents generally felt that studying for a degree 
would make their parents proud of them (five out of seven) and the same number felt that it would make their partner proud of them.

One of the questions which concerned support mechanisms (in terms of Schlossberg's [1] 4S model) was 'I really feel like I'm a part of the university where I am studying'. Six respondents disagreed with this statement and one neither agreed nor disagreed. In the context of support from the military itself, the results were similarly stark; none of the respondents had been given any study leave and none had had their workloads reduced to help with their studies. All seven respondents, however, had benefitted from funding being provided from the military to cover part of their university fees. Six out of the seven respondents reported that they tried to stay in touch with their fellow students on the programme.

It is, of course, difficult to draw any firm conclusions from questionnaire replies with such a small number of respondents. It was always probable that the qualitative data derived from the semi-structured interviews would prove more revealing. In the thirty minute semi-structured interviews from which the following three brief case studies are derived, respondents were asked to describe what the term 'military culture' meant to them. Whilst all three answers were distinctive, the phrases they used had thematic similarities. It is possible to summarise these similarities in four ways, in the voice of the respondents:

- There is a unique way that we as the military conduct ourselves - particularly our behaviours and our opinions.

- We pride ourselves on being robust and physical about the work we do.

- We have a drive for 'just getting things done', even if that requires improvising a $90 \%$ solution to a problem or staying up all night to get the job done - the mission is the most important thing.

- There's nothing we love more in the military than emphasising our divisions - but we would also (grudgingly) admit that, across the military, we have a lot in common.

Whilst undertaking an MSc programme is a transition in itself (as defined by Schlossberg), it can also be used to facilitate other, often concurrent, transitions. This may perhaps be the transition from the military back into civilian employment or from one job in the military to another more senior position. This is certainly the case with some of the respondents. One of them is making the transition from student to instructor whilst at the same time being promoted (from NCO to officer) and having the extra responsibility of a management role. One has just been selected for Staff College (PME) and will have to either rush completion of the MSc programme or put it 'on hold' until PME is complete. It is an explicit (yet puzzling) rule of PME that no other academic study is to be undertaken at the same time. Whilst these specific circumstances may be unique to the military, they have their similarities in the experiences of all part time postgraduate students - although it's possible that military life is more unpredictable than civilian employment.

The barriers to learning experienced by the three students in the brief case studies below could, perhaps, be more accurately described as barriers to studying. In the first case study, having a young child, combined with changes of circumstance and status meant that finding the time and 'head space' for study could be a problem. In the second case, the military drive for getting the job done means deriving a strategy to complete a dissertation in a short period of time. In the third case, two six month deployments in less than two years, both to locations that may euphemistically be described as 'less than hospitable' meant that the simple facilities that other students may take for granted (in this instance, a desk and chair) were simply not available. This, combined with a constant working routine of eighteen hours on and six hours off, gives little time for sleep - let alone study.

All three of those interviewed made the point that having the thirty minute Skype conversation had really helped them to revisit and to focus on their reasons for doing the Master's programme. Whilst a physical meeting between groups of students on the programme would be hard to arrange - they are dispersed widely across the World and have different working routines - a series of Webinars using an inexpensive software tool could be something that would enable mutual support for and by our students. It may be a small thing, but all three also mentioned the recommended course book as being of immense help they had all purchased it after the day schools. A small token of our support for new military students might be to buy the book for them all and hand it out at the start of the first day school. 
With the case studies in mind, rather than be concerned that so few of our students have, so far, completed their postgraduate programme, we should perhaps celebrate the fact that any of our serving military students manage to complete it at all. Master's degrees at our university are graded at one of three levels - Pass, Merit or Distinction. Of the four recent graduates from this specific programme, three have been awarded distinction.

In a busy world, there is never an ideal time to start a demanding programme of part time study - there will always be challenges, whether they come from the 'day job', family circumstances, elsewhere or from a combination of all three. It is how we - students, faculty, work, friends and family - rise to those challenges and offer support that ultimately determines our shared success or failure.

\section{REFERENCES}

[1] Schlossberg, N.K., 2005. Counseling adults in transition: Linking practice with theory. Springer Publishing Company.

[2] De Czege, H. W. (1997). How to change an army. Military Review, 77, 162.

[3] Ashcroft, M., 2014. The Veterans' Transition Review.

[4] Diramio, D., Ackerman, R. \& Mitchell, R. L. (2008). From combat to campus: Voices of studentveterans. NASPA Journal, 45.

[5] Schlossberg, N.K., 1981. Major contributions. Counseling Psychologist, 9(2), pp.2-15.

[6] Vitas, R.A., 1999. Civilian graduate education and the professional officer. Military Review, 79(3), p.47.

[7] Davis, R.L., 1989. The Case for Officer Professional Military Education. Airpower Journal, Winter, pp.34-45.

[8] Bower, M., 1966. The will to manage. McGraw-Hill.

[9] Handy, C.B., (1985) Understanding Organisations.

[10] DiRamio, D., Ackerman, R. and Mitchell, R.L., 2008. From combat to campus: Voices of studentveterans. Journal of Student Affairs Research and Practice, 45(1), pp.73-102.

[11] Pritchard, R. and Ashwood, E., 2008. Managing motivation: A manager's guide to diagnosing and improving motivation. Psychology Press.

[12] Maslow, A.H., 1943. A theory of human motivation. Psychological review,50(4), p.370.

[13] Herzberg, F.I., 1966. Work and the nature of man.

[14] Rosenberg, M. and McCullough, B.C., 1981. Mattering: Inferred significance and mental health among adolescents. Research in community \& mental health.

[15] Alderfer, C.P., 1969. An empirical test of a new theory of human needs. Organizational behavior and human performance, 4(2), pp.142-175.

[16] McClelland, D.C., 1987. Human motivation. CUP Archive.

[17] Schuler, H., Thornton, G., Frintrup, A. and Mueller-Hanson, R., 2004. AMI: Achievement Motivation Inventory: Technical and User's Manual. Hogrefe \& Huber.

[18] Swain, D.A., 1991. Withdrawal from sport and Schlossberg's model of transitions. Sociology of Sport Journal, 8(2), pp.152-160.

[19] Beausoleil-Holt, A.L., 2008. Challenge and Support: Facilitating Success of Soldiers in Degree Programs.

[20] Anderson, M.L., Goodman, J. and Schlossberg, N.K., 2011. Counseling Adults in Transition: Linking Schlossberg's 4S Theory With Practice in a Diverse World. 